\title{
KEKERABATAN BAHASA NAFRI, SENTANI, DAN TABLA: KAJIAN LEKSIKOSTATISTIK
}

\section{(THE RELATION OF NAFRI, SENTANI AND TABLA LANGUAGE A LEXICOSTATISTIC STUDY)}

\author{
Yohanis Sanjoko \\ Balai Bahasa Jayapura, Jalan Yoka, Waena, Distrik Heram, Jayapura \\ E-mail: triojoko55@yahoo.com \\ Telepon 0813344528976
}

\begin{abstract}
This research aims to find the relation between Nafri, Sentani and Tabla language. The researcher used lexicostatistical approach. Lexicostatistics is a technique in which language groupings tend to promote observation of words (lexicon) statistically. Through this technique, it is then possible to draw conclusion based upon similarity percentage and differences between one language and another. The results showed that Nafri, Sentani, and Tabla language come from one language family.
\end{abstract}

Key words: language relation, language family, lexicostatistics.

\begin{abstract}
Abstrak
Penelitian ini bertujuan untuk menemukan hubungan kekerabatan bahasa Nafri, bahasa Sentani, dan bahasa Tabla. Pendekatan yang digunakan adalah metode leksikostatistik. Adapun leksikostatistik merupakan suatu teknik dalam pengelompokkan bahasa yang cenderung mengutamakan peneropongan kata-kata (leksikon) secara statistik, untuk kemudian menarik kesimpulan berdasarkan persentase kesamaan dan perbedaan antara satu bahasa dengan bahasa yang lain. Hasil analisis menunjukkan bahwa antara bahasa Nafri, Sentani, dan Tabla merupakan satu rumpun bahasa (stok).
\end{abstract}

Kata Kunci: kekerabatan bahasa, rumpun bahasa, leksikostatistik

\section{Pendahuluan}

Bahasa Nafri, bahasa Sentani, dan bahasa Tabla yang dijadikan objek tulisan ini merupakan tiga bahasa yang digunakan oleh masyarakat etnik Nafri, Sentani, dan Tabla yang bermukim di Kota Jayapura dan Kabupaten Jayapura. Secara geografis wila- yah bahasa Nafri berbatasan langsung dengan bahasa Sentani sehingga fenomena bilingualisme tidak terhindarkan oleh penutur bahasa Nafri dan bahasa Sentani yang mendiami daerah transisi dalam berkomunikasi. Hal ini dapat diamati, misalnya, ketika diadakan hajatan bersama yang meli- 
batkan masyarakat penutur kedua bahasa tersebut, kedua bahasa sering digunakan serempak oleh kedua penutur bahasa itu. Demikian pula secara antropologis dan historis para penutur bahasa Nafri dan bahasa Sentani memiliki latar belakang yang sama. Hal ini terlihat dalam tuturan-tuturan adat yang biasa digunakan oleh kedua pemakai bahasa tersebut pada upacara-upacara adat. Biasanya, masyarakat Nafri dan Sentani mengisahkan kembali asal-usul para leluhur dan sejarah perpindahan penduduk serta silsilah.

Silzer (1986: 3) memasukkan bahasa Nafri ke dalam kelompok bahasa-bahasa dengan jumlah penutur kurang dari 5.000 orang. Penutur bahasa Nafri berjumlah 1.630 orang (Tachier, 1989: 19; Grimes, 2006: 49). Tachier mengelompokkan bahasa Nafri ke dalam rumpun bahasa Papua. Menurutnya, bahasa Nafri seasal dengan bahasa Sentani dan bahasa Tabla. Sementara itu, Grimes mengelompokkan bahasa Nafri ke dalam Trans-Nugini, bagian utama, tengah, dan barat.

Berkaitan dengan bahasa Sentani, menurut Tachier (1989: 20), penuturnya berjumlah 25.000 orang, sedangkan menurut Grimes (2006: 50) berjumlah 30.000 orang. Sementara itu, Silzer (1986: 3) hanya memasukkan bahasa Sentani ke dalam kelompok bahasabahasa dengan jumlah penutur lebih dari 5.000 orang. Bahasa Sentani termasuk dalam rumpun bahasa Papua (Tachier, 1989: 21). Adapun Grimes (2006: 52) memasukkannya ke dalam kelas Trans-Nugini. Bahasa Sentani memiliki tiga dialek, yaitu dialek Sentani Barat, Sentani Tengah, dan Sentani Timur (Tachier, 1989: 21; Grimes, 2006: 52).

Dalam Summer International of Linguistics (2006: 53) disebutkan bahwa bahasa Tabla (Tepera, Tanah Merah, Tabi, Tanah Merah 2, Jakari) meliputi Demta, Depapre, dan 13 desa di pesisir utara Teluk Tanah Merah bagian timur dan barat. Bahasa Tabla termasuk ke dalam kelas Trans-Nugini, bagian utama, tengah dan barat, Sentani, tepatnya di Sentani.

Bahasa Nafri, bahasa Sentani, dan bahasa Tabla memiliki fungsi, peranan, dan kedudukan yang sangat penting dalam tataran kehidupan masyarakatnya, yakni sebagai wahana untuk mengungkapkan identitas, budaya, dan perasaan serta untuk memahami dan mempelajari kearifan-kearifan lokal yang ada dan dimiliki, diyakini, serta diterima oleh masyarakat. Pengalaman empiris menunjukkan bahwa sampai dengan sekarang bahasa Nafri, bahasa Sentani, dan bahasa Tabla masih tetap digunakan oleh masyarakatnya sebagai bahasa pengantar pada kegiatan-kegiatan ekonomi (misalnya di pasar), kegiatan sosial (misalnya pada upacara pernikahan, kematian), dan acaraacara religius (misalnya ibadah rumah tangga).

Bahasa yang dimiliki penutur dalam suatu masyarakat merupakan hasil pengenalan (cognition) terhadap lingkungannya. Karena apa yang dilihat, dirasakan, didengar, dikecap, dan dicium dalam lingkungannya sama, bahasa yang dihasilkannya pun relatif menunjukkan adanya kesamaan. Kesamaan dan kemiripan wujud kebahasaan tersebut dapat mengarahkan kepada hipotesis mengenai hubungan kekerabatan di antara bahasa Nafri, bahasa Sentani, dan bahasa Tabla. Berdasarkan uraian tersebut, tulisan ini akan melihat kekerabatan antara bahasa Nafri, bahasa Sentani, dan bahasa Tabla secara leksikostatistik.

\section{Landasan Teori}

Menurut Mbete (2002: 3) sejumlah bahasa di kawasan tertentu dapat dihipotesiskan berkerabat yang bermula dari muasal yang tunggal. Ciri umum yang menunjang hipotesis ini adalah kemiripan dan kesamaan wujud kebahasaan. Satuan-satuan kebahasaan yang memiliki kesamaan/kemiripan 
bentuk dan makna tersebut dinamakan kata kerabat (kognat). Kesamaan/kemiripan itu tidak hanya dijelaskan sebagai pinjaman, kebetulan, ataupun kecenderungan semesta, tetapi juga dihipotesiskan sebagai warisan atau asal-usul yang sama.

Hubungan kekerabatan antara bahasabahasa sekerabat ini dapat dibuktikan dengan mengamati unsur-unsur warisan dari bahasa asal (proto bahasa) yang terdapat dalam bahasa-bahasa sekarang (Fernandez, 1996: 21). Metode yang paling andal dan sentral untuk membuktikan adanya hubungan kekerabatan dan kesejarahan ini adalah metode perbandingan (Anttila, 1972: 229; Campbell, 1998: 108). Perbandingan dilakukan untuk menemukan ciri-ciri kesamaan dan kebedaan antarbahasa kerabat yang hidup pada masa yang sama, dan untuk menjejaki proses perubahan dan penerusan serta merakit dan merancang bangun kembali sistem protobahasa sejumlah bahasa kerabat yang dihipotesiskan pernah hidup pada masa yang silam (Mbete, 2002: 5).

Hubungan kekerabatan sejumlah bahasa menghasilkan rumusan hipotetis bahwa tingkat keeratan bahasa itu berbeda-beda (Mbete, 2002: 5). Kejelasan tingkat keeratan hubungan kekerabatan tersebut dapat diketahui melalui pengelompokan (subgrouping). Dari pengelompokan bahasa-bahasa kerabat tersebut dapat diperoleh bermacam-macam tingkatan kelompok yang menunjukkan relasi antara bahasa-bahasa itu, dari bahasa yang mempunyai hubungan bersifat dialek hingga kepada bahasa kerabat yang mempunyai hubungan tingkat mikro filum (Keraf, 1996: 106). Di samping itu, dapat diketahui pula jumlah anggota yang membentuk tiap-tiap kelompok tersebut. Menurut Mbete (2002: 80) pengelompokan genetis bersifat non-arbritrar, bercirikan kaitan keseasalan, tuntas, dan unik. Semua bahasa dapat dikelompokkan secara tuntas, termasuk di dalamnya jenjang kesubkelom- pokan. Semua bahasa yang dikelompokkan itu berposisi dan beranggota tunggal dan berada pada suatu garis keturunan. Ini berarti tidak ada bahasa yang tidak masuk dalam satu kelompok.

Pengelompokan genetis dapat dilaksanakan dengan pendekatan kuantitatif. Melalui pendekatan kuantitatif pengelompokan didasarkan pada bukti-bukti kuantitatif yang berupa persentase persamaan katakata kognat. Pendekatan kuantitatif dilaksanakan dengan metode leksikostatistik. Leksikostatistik adalah suatu teknik dalam pengelompokan bahasa yang lebih cenderung mengutamakan peneropongan katakata secara statistik, untuk kemudian berusaha menetapkan pengelompokan itu berdasarkan persentase persamaan dan perbedaan suatu bahasa dengan bahasa lain. Selanjutnya, dapat dibuat tingkat kekerabatan antarbahasa dengan menghitung tingkat persamaan di antara kosakata dasarnya (Crowley, 1992: 168-169).

Daftar Swadesh yang terdiri atas dua ratus kosakata dasar dipandang oleh beberapa ahli sebagai daftar yang baku dalam metode ini. Menurut Keraf (1996: 126 - 129), teknik leksikostatistik dapat dilaksanakan dengan mengikuti langkah-langkah sebagai berikut.

1) Mengumpulkan kosakata dasar bahasa-bahasa kerabat.

2) Menetapkan pasangan-pasangan kosakata yang merupakan kognat. Sebuah pasangan kata akan dinyatakan sebagai kata kognat apabila memenuhi salah satu ketentuan berikut:

(a) pasangan kata itu identik, yaitu pasangan kata yang semua fonemnya sama betul;

(b) pasangan kata itu memiliki korespondensi fonemis;

(c) pasangan itu mirip secara fonetis;

(d) pasangan itu ada perbedaan satu fonem. 
3) Menghitung jumlah kognat di antara bahasa-bahasa kerabat. Untuk menghitung kata-kata kognat dari beberapa bahasa kerabat dilakukan langkah-langkah sebagai berikut:

(a) Mengeluarkan glos yang tidak diperhitungkan (kata-kata kosong), yaitu glos yang tidak ada katanya, baik dalam salah satu bahasa maupun dalam kesemua bahasa. Selain itu, semua kata pinjaman baik dari bahasa kerabat maupun dari bahasa nonkerabat juga merupakan glos yang tidak diperhitungkan.

(b) Mengisolasi morfem terikat. Datadata yang mengandung morfem terikat harus dipisahkan antara bentuk dasar dan semua morfem terikat yang melekat. Dengan melakukan pengisolasian morfem terikat akan lebih mudah apakah suatu pasangan menunjukkan kesamaan atau tidak.
Analisis kuantitatif dilakukan dengan teknik leksikostatistik. Penghitungan leksikostatistik ini dilakukan dengan rumus berikut.

$$
\begin{aligned}
& \Sigma \underline{\Sigma} \times 100 \%=\mathrm{d} \\
& \Sigma \mathrm{KB}
\end{aligned}
$$

$\Sigma \mathrm{K} \quad$ : jumlah persamaan kata kognat

$\Sigma K B$ : jumlah kata yang diperbandingkan

d : Persentase kekerabatan

Menurut Crowly (1992: 170), perbedaan persentase kognat akan menunjukkan tingkatan yang berbeda pengelompokan bahasa. Tingkatan yang berbeda dalam sub-grouping diberi nama yang berbeda pula. Tingkatantingkatan itu adalah sebagai berikut.

\begin{tabular}{|l|c|}
\hline \multicolumn{1}{|c|}{ Status } & $\begin{array}{c}\text { persentase persamaan kosa kata } \\
\text { dasar }\end{array}$ \\
\hline Bahasa & $81--100$ \\
\hline Keluarga & $36--81$ \\
\hline Stok/Rumpun & $12--36$ \\
\hline Mikrofilum & $4--12$ \\
\hline Mesofilum & $1--4$ \\
\hline Makrofilum & $0--1$ \\
\hline
\end{tabular}

\section{Pembahasan}

Untuk membahas 200 kosakata dasar bahasa Nafri, bahasa Sentani, dan bahasa Tabla sebagaimana yang disajikan di bawah ini, yang pertama dilakukan adalah mene- tapkan jumlah kata-kata berkerabat antara ketiga bahasa tersebut. Adapun jumlah kata yang berkerabat (kognat) antara bahasa Sentani, bahasa Nafri, dan bahasa Tabla dapat dilihat pada tabel 1 berikut. 
Tabel 1

Kata Berkerabat Bahasa Nafri, Bahasa, Sentani, dan Bahasa Tabla

\begin{tabular}{|c|c|c|c|c|}
\hline Nomor & Gloss & $1: 2$ & $1: 3$ & $2: 3$ \\
\hline 1 & $\mathrm{Abu}$ & - & - & - \\
\hline 2 & Air & + & + & + \\
\hline 3 & Akar & - & - & - \\
\hline 4 & alir (me) & - & - & - \\
\hline 5 & Anak & - & - & - \\
\hline 6 & Angin & - & - & - \\
\hline 7 & Anjing & + & + & + \\
\hline 8 & Apa & - & - & - \\
\hline 9 & Api & + & - & - \\
\hline 10 & apung (me) & + & - & - \\
\hline 11 & Asap & - & - & - \\
\hline 12 & Awan & + & - & + \\
\hline 13 & Ayah & + & - & - \\
\hline 14 & Bagaimana & - & - & - \\
\hline 15 & Baik & - & - & + \\
\hline 16 & Bakar & - & - & - \\
\hline 17 & Balik & + & - & - \\
\hline 18 & Banyak & - & - & - \\
\hline 19 & Baring & + & - & - \\
\hline 20 & Baru & - & - & - \\
\hline 21 & Basah & - & - & - \\
\hline 22 & Batu & + & - & - \\
\hline 23 & Beberapa & - & - & - \\
\hline 24 & belah (me) & + & - & - \\
\hline 25 & Benar & + & - & - \\
\hline 26 & Bengkak & - & - & - \\
\hline 27 & Benih & - & - & - \\
\hline 28 & Berat & - & - & - \\
\hline 29 & Berenang & - & - & - \\
\hline 30 & Beri & + & - & - \\
\hline
\end{tabular}




\begin{tabular}{|c|c|c|c|c|}
\hline 31 & Berjalan & - & - & - \\
\hline 32 & Besar & - & - & - \\
\hline 33 & Bilamana & - & - & - \\
\hline 34 & Binatang & - & - & - \\
\hline 35 & Bintang & - & + & - \\
\hline 36 & Buah & - & - & + \\
\hline 37 & Bulan & + & + & - \\
\hline 38 & Bulu & + & - & - \\
\hline 39 & Bunga & - & - & - \\
\hline 40 & Bunuh & - & - & - \\
\hline 41 & buru (ber) & - & - & - \\
\hline 42 & Buruk & - & - & + \\
\hline 43 & Burung & + & + & + \\
\hline 44 & Busuk & - & - & - \\
\hline 45 & Cacing & - & - & - \\
\hline 46 & Cium & - & - & - \\
\hline 47 & Cuci & - & - & - \\
\hline 48 & Daging & - & - & - \\
\hline 49 & Dan & - & - & - \\
\hline 50 & Danau & - & - & - \\
\hline 51 & Darah & + & + & + \\
\hline 52 & Dating & + & - & - \\
\hline 53 & Daun & + & - & - \\
\hline 54 & Debu & + & + & - \\
\hline 55 & Dekat & + & + & + \\
\hline 56 & Dengan & - & - & - \\
\hline 57 & Dengar & + & - & - \\
\hline 58 & di dalam & - & - & - \\
\hline 59 & di mana & - & - & - \\
\hline 60 & di sini & - & - & - \\
\hline 61 & di situ & - & - & - \\
\hline
\end{tabular}




\begin{tabular}{|c|c|c|c|c|}
\hline 62 & Dada & - & + & - \\
\hline 63 & Dingin & - & - & - \\
\hline 64 & diri (ber) & - & - & - \\
\hline 65 & Dorong & - & - & - \\
\hline 66 & Dua & + & + & + \\
\hline 67 & Duduk & + & - & - \\
\hline 68 & Ekor & - & + & + \\
\hline 69 & Empat & - & - & - \\
\hline 70 & Engkau & + & + & + \\
\hline 71 & Gali & + & - & - \\
\hline 72 & Garam & + & - & - \\
\hline 73 & Garuk & - & - & - \\
\hline 74 & gemuk, lemak & - & - & + \\
\hline 75 & Gigi & - & - & - \\
\hline 76 & Gigit & - & - & - \\
\hline 77 & Gosok & - & - & - \\
\hline 78 & Gunung & + & + & + \\
\hline 79 & Hantam & - & - & - \\
\hline 80 & Hapus & - & - & - \\
\hline 81 & Hati & - & - & + \\
\hline 82 & Hidung & - & - & - \\
\hline 83 & Hidup & + & + & + \\
\hline 84 & Hijau & - & - & - \\
\hline 85 & Hisap & - & - & - \\
\hline 86 & Hitam & - & - & + \\
\hline 87 & Hitung & - & - & - \\
\hline 88 & Hujan & - & + & - \\
\hline 89 & Hutan & - & - & - \\
\hline 90 & Ia & + & + & + \\
\hline 91 & $\mathrm{Ibu}$ & + & + & - \\
\hline 92 & Ikan & + & + & + \\
\hline
\end{tabular}




\begin{tabular}{|c|c|c|c|c|}
\hline 93 & Ikat & - & - & - \\
\hline 94 & Ini & + & + & + \\
\hline 95 & Isteri & - & + & + \\
\hline 96 & Itu & + & + & + \\
\hline 97 & Jahit & - & - & - \\
\hline 98 & jalan (ber) & - & - & - \\
\hline 99 & Jantung & - & - & - \\
\hline 100 & Jatuh & - & - & - \\
\hline 101 & Jauh & - & - & - \\
\hline 102 & Kabut & + & - & + \\
\hline 103 & Kaki & + & + & + \\
\hline 104 & Kalau & - & - & - \\
\hline 105 & kami, kita & + & - & - \\
\hline 106 & Kamu & - & - & - \\
\hline 107 & Kanan & - & + & - \\
\hline 108 & Karena & - & - & - \\
\hline 109 & kata (ber) & + & + & + \\
\hline 110 & Kecil & - & - & - \\
\hline 111 & kelahi (ber) & - & - & - \\
\hline 112 & Kepala & - & - & - \\
\hline 113 & Kering & - & - & - \\
\hline 114 & Kiri & - & - & + \\
\hline 115 & Kotor & + & + & + \\
\hline 116 & Kuku & - & - & - \\
\hline 117 & Kulit & + & - & - \\
\hline 118 & Kuning & - & - & + \\
\hline 119 & Kutu & + & + & + \\
\hline 120 & Lain & + & + & + \\
\hline 121 & Langit & + & - & - \\
\hline 122 & Laut & + & + & - \\
\hline 123 & Lebar & + & - & - \\
\hline
\end{tabular}




\begin{tabular}{|c|c|c|c|c|}
\hline 124 & Leher & - & - & - \\
\hline 125 & Lelaki & - & - & + \\
\hline 126 & Lempar & - & - & - \\
\hline 127 & Licin & - & - & - \\
\hline 128 & Lidah & + & + & + \\
\hline 129 & Lihat & + & - & - \\
\hline 130 & Lima & + & - & - \\
\hline 131 & Ludah & - & - & - \\
\hline 132 & Lurus & - & - & - \\
\hline 133 & Lutut & - & - & - \\
\hline 134 & Main & - & - & - \\
\hline 135 & Makan & + & - & - \\
\hline 136 & Malam & - & - & - \\
\hline 137 & Mata & - & - & - \\
\hline 138 & Matahari & - & - & + \\
\hline 139 & Mati & - & - & - \\
\hline 140 & Merah & - & + & - \\
\hline 141 & Mereka & + & + & + \\
\hline 142 & Minum & + & + & + \\
\hline 143 & Mulut & + & - & - \\
\hline 144 & Muntah & + & + & + \\
\hline 145 & Nama & + & - & - \\
\hline 146 & Napas & + & + & + \\
\hline 147 & Nyanyi & - & - & - \\
\hline 148 & Orang & - & - & - \\
\hline 149 & Panas & + & + & - \\
\hline 150 & Panjang & - & - & - \\
\hline 151 & Pasir & - & - & - \\
\hline 152 & Pegang & - & - & - \\
\hline 153 & Pendek & + & - & - \\
\hline 154 & Peras & - & - & - \\
\hline
\end{tabular}




\begin{tabular}{|c|c|c|c|c|}
\hline 155 & Perempuan & - & + & - \\
\hline 156 & Perut & - & - & - \\
\hline 157 & Piker & + & - & - \\
\hline 158 & Pohon & + & + & + \\
\hline 159 & Potong & - & - & - \\
\hline 160 & Punggung & - & - & + \\
\hline 161 & Pusar & - & + & - \\
\hline 162 & Putih & - & - & - \\
\hline 163 & Rambut & - & - & - \\
\hline 164 & Rumput & - & - & - \\
\hline 165 & Satu & + & + & + \\
\hline 166 & Saya & - & - & - \\
\hline 167 & Sayap & - & - & - \\
\hline 168 & Sedikit & - & - & - \\
\hline 169 & Sempit & + & - & - \\
\hline 170 & Semua & - & - & - \\
\hline 171 & Siang & + & + & + \\
\hline 172 & Siapa & - & - & - \\
\hline 173 & Suami & - & - & - \\
\hline 174 & Sungai & - & - & - \\
\hline 175 & Tahu & - & - & - \\
\hline 176 & Tahun & - & - & - \\
\hline 177 & Tajam & - & - & + \\
\hline 178 & Takut & + & - & - \\
\hline 179 & Tali & + & + & + \\
\hline 180 & Tanah & - & - & + \\
\hline 181 & Tangan & + & - & + \\
\hline 182 & Tarik & - & - & - \\
\hline 183 & Tebal & - & - & - \\
\hline 184 & Telinga & - & - & - \\
\hline 185 & Telur & + & - & - \\
\hline
\end{tabular}




\begin{tabular}{|c|c|c|c|c|}
\hline 186 & Terbang & - & - & - \\
\hline 187 & Tertawa & - & - & - \\
\hline 188 & Tetek & - & - & - \\
\hline 189 & Tidak & - & + & - \\
\hline 190 & Tidur & - & - & - \\
\hline 191 & Tiga & + & + & + \\
\hline 192 & tikam (me) & - & - & - \\
\hline 193 & Tipis & - & + & - \\
\hline 194 & Tiup & - & - & - \\
\hline 195 & Tongkat & + & - & - \\
\hline 196 & Tua & - & - & - \\
\hline 197 & Tulang & - & + & - \\
\hline 198 & Tumpul & - & - & - \\
\hline 199 & Ular & - & + & - \\
\hline 200 & Usus & - & - & - \\
\hline \multicolumn{2}{|c|}{ Kognat } & 68 & 46 & 45 \\
\hline
\end{tabular}

Keterangan:

$1=$ bahasa Nafri

$2=$ bahasa Sentani

$3=$ bahasa Tabla

$+=$ kognat

Setelah memperhatikan senarai 200 kosakata dasar swadesh bahasa Nafri, bahasa Sentani, dan bahasa Tabla di atas dan mengikuti prosedur kerja kajian leksikostatistik, dapat ditentukan bahwa jumlah kata yang berkerabat antara bahasa Nafri dan bahasa Sentani adalah 68 kata, bahasa Nafri dan bahasa Tabla adalah 46 kata, serta bahasa Sentani dan bahasa Tabla adalah 45 kata. Setelah menetapkan jumlah kata kerabat, yang dilakukan selanjutnya adalah membagi jumlah kata yang berkerabat dengan jumlah kosakata yang diperbandingkan. Cara mendapatkan jumlah persentase kata kerabat seperti yang dilakukan di bawah ini.
Bahasa Nafri dan bahasa Sentani $\underline{68} \times 100 \%=34 \%$ 200

Bahasa Nafri dan bahasa Tabla $\underline{46} \times 100 \%=23 \%$

200

Bahasa Sentani dan bahasa Tabla $\underline{45} \times 100 \%=22.5 \%$

200

Hasil perhitungan leksikostatistik tersebut memperlihatkan bahwa bahasa Nafri, bahasa Sentani, dan bahasa Tabla merupakan bahasa yang berkerabat. Kekerabatan bahasa Nafri dan Sentani adalah 34\%, kekerabatan bahasa Nafri dan bahasa Tabla adalah 23\%, serta kekerabatan bahasa Sentani dan bahasa Tabla adalah $22.5 \%$. Persen- 
tase kekerabatan ketiga bahasa tersebut

dapat dilihat pada tabel 2 di bawah ini.

Tabel 2 Persentase Kekerabatan

\begin{tabular}{|l|l|l|l|}
\hline & Nafri & \multicolumn{2}{|l}{} \\
\cline { 1 - 2 } Nafri & $=$ & Sentani & \\
\hline Sentani & 34 & $=$ & Tabla \\
\hline Tabla & 23 & 22,5 & $=$ \\
\hline
\end{tabular}

Hasil persentase hubungan kekerabatan bahasa tersebut menunjukkan apakah bahasa Sentani, Nafri, dan Tabla adalah bahasa $(81 \%-100 \%)$, keluarga $(36 \%-80 \%)$, stok/ rumpun $(12 \%-36 \%)$, mikrofilum $(4 \%-12 \%)$, mesofilum $(1 \%-4 \%)$, atau makrofilum (kurang dari1\%).

Menurut Multamia dkk. (2000: 22) supaya tingkat kekerabatan yang telah dinyatakan dalam angka-angka itu lebih sederhana, angka-angka persentase rata-rata itu dikonversikan ke dalam bagan silsilah kekerabatan. Untuk itu, mula-mula sepasang bahasa yang memiliki persentase paling tinggi dihubungkan satu sama lain. Persentase kekerabatan paling tinggi di antara ketiga bahasa tersebut adalah antara bahasa Nafri dengan bahasa Sentani sebanyak 34\%. Dengan demikian, di antara kedua bahasa tersebut dibuat garis penghubung. Setelah kedua bahasa tersebut (Nafri dan Sentani) dihubungkan, dicarilah hubungan antara bahasa-bahasa tersebut dengan bahasa yang belum disebutkan, yaitu bahasa Tabla. Untuk mengetahui hubungan antara ketiga bahasa tersebut, diperlukan langkah-langkah untuk mencari rata-rata.

Langkah pertama dalam mencari ratarata adalah dengan menjumlahkan persentase kekerabatan antara bahasa Tabla-bahasa Sentani dengan persentase kekerabatan bahasa Tabla-bahasa Nafri kemudian dibagi dua. Hasil yang diperoleh yaitu sebesar $22,3 \%$. Hasil perhitungan tersebut digambarkan dalam bagan berikut.

\section{Bagan Kekerabatan Bahasa Nafri, Bahasa Sentani, dan Bahasa Tabla}

10

20

22,3

30

40

50

60

70

80

90

100

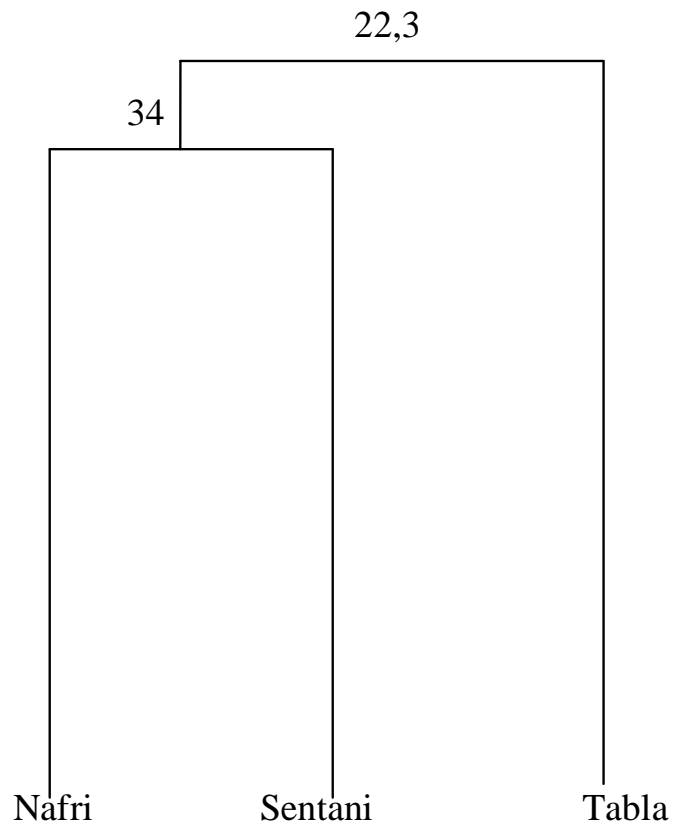

Berdasarkan bagan silsilah di atas dan juga penentuan kekerabatan dapat disimpulkan bahwa bahasa Nafri dan Sentani termasuk dalam rumpun (stock) bahasa yang 
sama dengan persentase $34 \%$. Sementara itu, antara bahasa Tabla dan bahasa Nafri dan Sentani juga termasuk dalam satu rumpun (stock) dengan persentase 22,3\%. Singkatnya, ketiga bahasa tersebut merupakan bahasa dalam satu rumpun yang sama.

Meskipun ketiganya termasuk ke dalam rumpun yang sama, tentu ada bahasa yang lebih dekat satu dengan yang lain. Oleh sebab itu, perlu digambarkan kedekatannya. Dari persentase di bagian depan tampak bahwa bahasa Sentani dan Nafri berhubungan lebih dekat dibandingkan dengan bahasa Tabla. Secara sederhana dapat digambarkan dalam diagram di bawah ini.

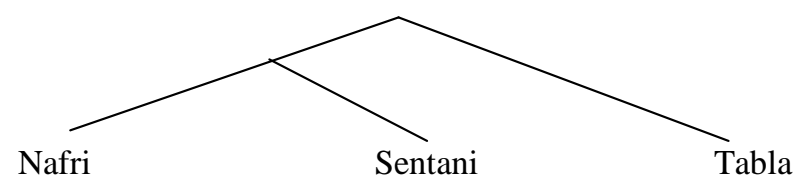

Dari diagram pohon di atas diketahui bahwa bahasa Nafri, Sentani, dan Tabla berada dalam satu rumpun yang sama.

\section{Penutup}

Berdasarkan uraian di depan tampak bahwa persentase kata kerabat antara bahasa Nafri dan Bahasa Sentani sebesar 34\%, bahasa Nafri dan Bahasa Tabla sebesar 23\%, serta bahasa Sentani dan bahasa Tabla sebesar $22.5 \%$ sehingga dapat dikatakan merupakan satu rumpun bahasa (stock). Hal ini senada dengan Tachier yang mengelompokkan bahasa Nafri, bahasa Sentani, dan bahasa Tabla ke dalam satu rumpun bahasa. Menurut Tachier, bahasa Nafri seasal dengan bahasa Sentani dan bahasa Tabla.

\section{Daftar Pustaka}

Anttilla, Raimo.1972. An Introduction to Historical and Comparative Linguistics. New York: Macmillan.

Campbell, Lyle. 1998. Historical Linguistics: An Introduction. Edinburgh: Edinburh University.

Crowley, Terry.1992. An Introduction to Historical Linguistics .Auckland: Oxford University Press.

Fernandez, Inyo. 1996. Relasi Historis Kekerabatan Bahasa Flores (Kajian Linguistik Historis Komparatifterhadap Sembilan Bahasa di Flores). Yogyakarta: Nusa Indah.

Grimes, Barbara F. (Ed). 2006. Bahasa-Bahasa di Indonesia. Jakarta: SIL International Cabang Indonesia.

Keraf, Gorys A. 1996. Linguistik Bandingan Historis. Jakarta: Gramedia Pustaka Utama.

Mbete, Aron Meko. 2002. Metode Linguistik Diakronis. Denpasar: Universitas Udayana.

Multamia, dkk. 2000. Kekerabatan dan Pemetaan Bahasa-Bahasa di Provinsi Nusa Tenggara Timur. Jakarta: Pusat Pembinaan dan Pengembangan Bahasa, Departemen Pendidikan Nasional.

Silzer, Peter J. 1986. "Peta Lokasi BahasaBahasa Daerah di Propinsi Irian Jaya". Jayapura: Universitas Cendrawasih dan Summer Institute of Linguistic.

Tachier, A. 1991. "Bahasa-Bahasa Suku Bangsa di Irian Jaya". Jayapura: Kantor Wilayah Departemen Pendidikan dan Kebudayaan Provinsi Irian Jaya. 
